\title{
ENSINO DE CAMPO: SUA IMPORTÂNCIA NA FORMAÇÃO DO ENFERMEIRO *
}

\author{
Eliane Corrêa Chaves** \\ Estela Regina Ferraz*** \\ Shizuka Ishii **** \\ Suely Itsuko Ciosak ***** \\ Ana Maria K. Miyadahira**
}

CHAVES, E. C.; FERRAZ, E. R.; ISHII, S.; CIOSAK, S. I.; MIYADAHIRA, A. M. K. Ensino de campo: sua importância na formação do enfermeiro. Rev. Esc. Enf. USP, São Paulo, 15(2):135-140, 1981.

As autoras abordam o ensino de campo como elemento essencial na formação de enfermeiros, dando suas características, vantagens e requisitos.

O ensino de campo é elemento indispensável do sistema de formação de enfermeiros. Consiste em toda instrução dada a estudantes de enfermagem durante o período de prática, nas instituições de saúde, hospitalares ou para-hospitalares.

Segundo CARVALHO 2, "o ensino clínico é a essência do ensino na enfermagem. A experiência clínica consome a maior parte do tempo destinado a uma disciplina de enfermagem e não poderia ser de outra maneira, uma vez que a profissão é essencialmente técnica e exige prática no campo, anterior ao seu exercício. Essa prática, porém, não é desligada do conteúdo teórico do curso; as professoras acompanham os alunos no estágio e junto ao doente continuam ensinando, corrigindo falhas e orientando. Há sempre uma proporção razoável de tempo de aprendizagem, para cada aluno, dentro do período de experiência clínica chamado de instrução ou ensino clínico, que poderá ou não ser programado antecipadamente".

Para HEIDGERKEN ${ }^{4}$, o ensino de campo engloba o ensino de caso (em aula, utilizando dados colhidos na comunidade), o laboratório de ciências aplicadas e o meio clínico como o hospital, serviço da comunidade.

Para CARVALHO ${ }^{2}$, o ensino clínico consiste na instrução dada aos alunos no ambiente de trabalho (enfermaria) ou em sala de aula, relacionado com o tratamento e com a assistência de enfermagem e um determinado doente ou grupo de doentes. Consiste, portanto, em suplementar o ensino teórico: em ensinar o estudante a prestar assistência completa de enfermagem, em ajudá-lo a aplicar os seus conhecimentos teóricos na prática diária com os seus pacientes, em estimular seu desenvolvimento intelectual e técnico.

* Trabalho apresentado a disciplina Problemas do Ensino de Enfermagem, no Curso de Pós-Graduacão, nível de Mestrado da EEUSP, 1980.

* * Auxiliar de Ensino da disciplina Enfermagem Médico-Cirúrzica da EEUSP.

*** Auxiliar de Ensino da disciplina Enfermagem em Centro Cirúrzico da EEUSP.

**** Enfermeira-Assistente Técnico da Divisăo de Enfermagem do Instituto do Coração do Hospital das Clíníicas da FMUSP.

**** Auxiliar de Ensino da disciplina Enfermagem em Doenças Transmissíveis da EEUSP. 
De acordo com a legislação brasileira vigente, Resolução do Conselho Federal de Educação n. ${ }^{\circ}$ 04/72, baseado no Parecer n. ${ }^{\circ} 163 / 72$ do mesmo Conselho que estabelece o currículo mínimo dos cursos de Graduação em Enfermagem e Obstetrícia, artigo $8 .^{\circ}$, alínea $a$, verificamos que na habilitação geral de Enfermeiro, são necessários 2.500 horas de atividades, integralizáveis no mínimo em três anos letivos. No artigo 9..$^{\circ}$ encontramos "na moddalidade geral de Enfermeiro e em todas as habilitaçôes será exigido o Estágio Supervisionado em hospital e em outros serviços médico-sanitários a critério da Instituição, com carga horária não inferior a um terço da correspondente à parte ou partes profissionalizantes do currículo e levado a efeito durante todo o transcurso idesse período de formaçãa" ${ }^{2}$.

$\mathrm{Na}$ análise feita por PINHEIRO ${ }^{5}$, sobre a Portaria n. ${ }^{\circ} 159 / 65$, do Ministro da Educação e Cultura, que homologa o Parecer n. ${ }^{\circ} 52 / 65$ e respectivo adendo aprovado pelo conselho Federal de Educação a autora chega às seguintes conclusões:

1. "As escolas de enfermagem devem ter docentes de enfermagem para o ensisino e supervisão dos estudantes no campo de estágio, na proporção aproximada de um docente para oito alunos, a fim de possibilitar o ensino clínico.

2. As docentes das cadeiras de enfermagem devem computar todo o ensino clínico, planejado e incidental, por ser esta a forma de ensino que além de apresentar maior possibilidade de fixação de aprendizagem, evidencia o número real de horas de instrução.

3. As escolas que não dispõem de recursos financeiros para contratar enfermeiras educadoras em número suficiente para o ensino clínico e consequentemente não podem atingir o termo médio de horas de ensino exigidas para realizar o curso em três anos, deverão retardar o rítmo do curso, se necessário, até o limite mínimo de integralização de horas úteis, que é o do curso em cinco anos".

Vê-se portanto que apesar das conclusões acima terem sido redigidas em 1968, e de haver parecer mais recente do CFE, de 1972, já citado, a situação do estágio de campo não difere da atual.

\section{Características do ensino clínico}

O ensino clínico ou de campo deve ser planejado, avaliado e implementado de tal forma que proporcione o maior aproveitamento dos alunos. Para tanto, há necessidade de que o professor planeje atividade de campo coerente com a teoria e com os objetivos propostos. O professor deve ter em mente: atividades dos estudantes, orientação necessária, dificuldades a serem encontradas e qualidade do trabaJho esperado.

Para escolha do local de estágio é importante lembrar que os estudantes sofrem um processo de interação com o ambiente físico e psicológico do campo. $O$ interrelacionamento com todo o seu pessoal que inclue os integrantes de diversas categorias de profissionais de saúde, pessoal administrativo, de serviços técnicos e os próprios pacientes, exerce grande influência na formação do aluno, que aprenderá através dos exemplos, bons ou maus.

Segundo SCHWEER \& GEBBIE ${ }^{6}$, as habilidades que serão descnvolvidas no aluno, no campo de estágio, podem ser classificadas em: 
a . de observação: indispensável para a determinação de ações apropriadas ao cuidado do paciente; embora o campo de estágio propicie amplas oportunidades para desenvolver a capacidade de observação, não assegura que o aluno desenvolva automaticamente esta habilidade de modo seletivo; através do uso dos vários sentidos o aluno pode aprender a observar as expressões faciais do paciente, movimentos corporais, postura, etc. e verificar as inconsistências entre a comunicação verbal e não verbal; e inerente a isto o desenvolvimento da percepção seletiva, interpretação e julgamento que levam à ação positiva.

b. de relacionamento interpessoal, que envolve: 1) compreensão dos sentimentos, capacidade, limitações e o grau de aceitação desses fatores; 2) desenvolvimento do próprio potencial; 3 ) compreensão do comportamento do paciente e sua familía, aceitando seus valores e ajudando-os a atingir seu potencial máximo; 4) estabelecimento de ambiente terapêutico para interação enfermeiro-paciente; 5) estabelecimento de relacionamento efetivo entre o paciente, sua família, o médico e outros que contribuem com seu bem-estar; e 6) estabelecimento de relacionamento efetivo com o pessoal de enfermagem e outros membros da equipe de saúde.

c. na aplicação de conceitos e princípios científicos às situações clínicas: é essencial no ensino clínico, o desenvolvimento de habilidade para utilizar o conhecimento das várias ciências e da teoria de enfermagem; seria irreal supor que os estudantes lembrassem de aplicar os conceitos e princípios na situação clínica; cabe ao professor, juntamente com os alunos, utilizar estas informações básicas para avaliar as necessidades, estabelecer e implementar um plano de ação para atender a estas necessidades.

d. em fazer julgamento, envolve: 1) reconhecimento de sinais e sintomas do paciente; 2) análise desses sinais e sintomas para chegar a um diagnóstico de enfermagem; 3) desenvolvimento e implementação de um plano de ação de enfermagem; 4) avaliação do cuidado fazendo-se os ajustamentos necessários; 5 ) interpretação e registro das observações; 6) coordenação da equipe e 7) ensino ao paciente de acordo com suas necessidades e capacidade de assimilação.

e. motora: os alunos de enfermagem precisam desenvolver várias habilidades motoras de modo a prestar cuidado seguro de enfermagem; um programa de ensino clínico deve prever; 1) desenvolvimento da habilidade motora; 2) conhecimento de equipamentos eletrônicos e mecânicos e a interpretação de seus resultados e 3 ) moIdificação da habilidade motora para atender as necessidades do paciente numa determinada situação.

Para que o aluno desenvolva seu potencial ao máximo durante o ensino clínico o professor deve auxiliá-lo:

- no planejamento e organização das atividades diárias, considerando a utilização do tempo, energia e material;

- na aplicação de conceitos e princípios na situação clínica. A aprendizagem é mais efetiva quando o professor questiona sistematicamente o aluno: por que o paciente apresenta determinado comportameno? Por que certos sintomas são indicativos de certas manifestações clínicas? etc.. Isto ajuda o aluno a relacio- 
nar o conhecimento teórico e a experiência clínica além de nele desenvolver o hábito de questionar;

- no desenvolvimento de relação interpessoal. Um curso sobre dinâmica da comunicação pode ajudar o aluno a desenvolver um relacionamento efetivo no campo de estágio;

- a fazer julgamentos. 0 processo de enfermagem que envolve um plano de cuidado escrito implica em julgamento, uma vez que este plano é baseado num diagnóstico e

- no desenvolvimento de habilidades motoras. Como as habilidades aprendidas em laboratório tendem a degenerar, quando não são imediatamente seguidas pela experiência numa situação real, o professor deve dar ao aluno a oportunidade de aplicação imediata da habilidade na prática.

É aconselhável que, após cada dia de estágio, o professor faça com os alunos reunião de avaliação do planejamento executado bem como de estudo completo da assistência prestada ao paciente, porém, há dificuldades para tal avaliação que deverá abranger os seguintes ítens:

- aquisição de conhecimentos teórico e prático;

- capacidade de aplicá-los;

- execução dos procedimentos de enfermagem;

- comportamentos e atitudes pessoais e

- avaliação individual de cada aluno.

Para eficiência de todo o planejamento do ensino de campo, há necessidade de que o campo de estágio preencha alguns requisitos, como apontam GARCIA \& RI$\mathrm{BEIRO}^{3}$, para a realidade brasileira:

a. Serviço de Enfermagem dirigido por enfermeiro e prestando boa assistência de enfermagem;

b. Direção do Serviço de Enfermagem feita por enfermeiro com autonomia de resolução de problemas de enfermagem;

c. número adequado de pessoal de enfermagem, sendo que os alunos não suprirão faltas.

d. pelo menos um enfermeiro-chefe em cada serviço básico: clínica, cirúrgica, centro cirúrgico, pediatria e obstetrícia;

e. manter programa de educação em serviço;

f. ter regulamento e sistema de anotação adequado;

g. observância do código de ética e

h. oferecer boas condições de trabalho, material e equipamentos adequados. 
Além disso, as mesmas autoras apontam a necessidade de:

- reuniōes periódicas do corpo de enfermeiros para análise do Serviço de Enfermagem;

- necessidade de enviar enfermeiros para cursos de pós graduação e

- motivação dos serviços do hospital-escola para realização de estudos e pesquisa em enfermagem.

Como conclusão, descrevemos algumas normas para o emprego do ensino de campo ${ }^{4}$ :

a respeitar os alunos, pacientes, médicos e demais pessoal, pois o ser humano é uma pessoa que tem direito ao respeito, vida pessoal e dignidade humana;

b. respeitar cada estudante como um indivíduo, que tem seus próprios interesses, necessidades e capacidades;

c. planejar objetivos adequados, para o ensino teórico e prático de cada estudante;

d. avaliar e ajudar o estudante a desenvolver conhecimentos especificos de acordo com a quantidade de conhecimentos e habilidades;

e. selecionar atividades, experiências didáticas na clínica, de acordo com conhecimentos e grau de habilidade de cada aluno;

f. adaptar o ensino às capacidades e às necessidades de cada estudante;

g. tornar o estudante capaz de enfrentar novos métodos e situações sem muito esforço, sem temores e com segurança;

h. levar o aluno a progredir pessoal e profissionalmente durante sua expcriência clínica, através de discussões e avaliações;

i. estimular o aluno a se tornar independente, porém ajudá-lo se necessário.

CHAVES, E. C.; FERRAZ, E. R.; ISHII, S.; CIOSAK, S. I.; MIYADAHIRA, A. M. K. Clinical teaching: its importance in nurses's training. Rev. Esc. Enf. USP, São Paulo, $15(2): 135-140,1981$.

The authors describe the clinical teaching as an essential element in nurses's training, giving its characteristics, advantages and requirements.

\section{REFERENCIAS BIBLIOGRAFICAS}

1. BRASIL. Leis, decretos etc. Resolução n.o 4/72. In: BRASIL. Ministério da Saúde. Enfermagem: legislação e assuntos correlatos. Rio de Janeiro, Fundação Serviço Especial de Saúde Pública, 1974. v. 3 , p. $722-4$.

2. Carvalho, A. C. Consideraçōes sobre o ensino de campo na enfermagem. Rev. Esc. Enf. USP, Sāo Paulo, 5 (4): 149-53, out./dez. 1972.

3. GARCIA, L. T. \& RIBEIRO, C. M. Padróes mínimos para o campo de prática de estudantes de enfermagem. Rev. Bras. Enf., Rio de Janeiro, 21 (5): 369-74, out. 1968.

4. HEIDGERKREN, L. E. Enseñanza en las escuelas de enfermería. 3. ed. México, Interamericana, 1966. p. 343-56.

5. PINHEIRO, M. R. S. Consideraçōes sobre a carga horária do curso de graduação em Enfermagem geral. Rev. Esc. Enf. USP, Săo Paulo, 2 (1): 9-17, mar. 1968.

6. SCHWEER, J. E. \& GEBBIE, K. M. Creative teaching in clinical nursing. 3. ed. Saint Louis, Mosby, 1976. cap. 6/7, p. 67-104. 


\section{BIBLIOGRAFIA}

CALDAS, N. P. Responsabilidade do docente de enfermagem em relação ao campo clínico. Rev. Bras. Enf., Brasília, 21 (5): 389-95, out. 1968.

CARVAluo, A. C. Programação das cadeiras de enfermagem. Rev. Esc. Ent. USP, São Paulo, 2 (1): 17-27, mar. 1968.

COSTA, L. A. T. et alii. Integração ensino-serviço: estudo preliminar na UNB. Rev. Bras. Enf., Brasflia, 31 (2): 222-6, abr./jun. 1978.

DOURADO, H. G. Abordagens novas na atenção de enfermagem e a necessidade de comunicação entre os enfermeiros dos serviços e do ensino. Rev. Bras. Enf., Brasilia, 29 (1): 64-8, jan./mar. 1976.

FORJAS, M. Ensino clínico. Rev. Bras. Enf., Rio de Janeiro, 10 (2): 149-62, Jun. 1967.

MC CAFFERY, M. What is the students learning in the clinical laboratory? J. Nurs. Educ., New Jersey, 7 (4): 3-10, Nov. 1968.

MOREIRA, E. D. Integração ensino e serviço de enfermagem do INPS na integração servico-escola. Rev. Bras. Enf., Brasília, 28 (3): 42-7, jul./set. 1975.

OLIVEIRA, M. I. R. Porque integrar ensino e serviço de enfermagem nos hospitais universitários. Rev. Bras. Enf., Brasilia, 28 (3): 37-41, ful./set. 1975.

Responsabilidade do docente de enfermagem em relação ao campo clínico. Rev. Bras. Enf., Brasilia, 21 (5): 389-95, 1968.

RESENDE, M. A. Ensino de enfermagem. Rev. Bras. Enf., Brasília, 14 (2): 110-58, abr. 1961. 